\title{
ILAR
}

\section{Validation of a Method for Measuring Sperm Quality and Quantity in Reproductive Toxicity Tests with Pair-Breeding Male Fathead Minnows (Pimephales promelas)}

\author{
David N. Hala, Katrien Van Look, William V. Holt, and Susan Jobling
}

ILAR e-Journal Volume 50(e1-e10) - 2009

ILAR e-Journal is the online, periodic, peer-reviewed publication of the Institute for Laboratory Animal Research (ILAR), The National Academies, 500 Fifth Street, NW, Washington, DC 20001; Tel: 202-334-2590; Fax: 202-334-1687; E-mail: ILARJ@nas.edu; URL: www.national-academies.org/ilar. Membership in the ILAR Associates Program includes four issues of ILAR Journal per year. Subscribe: Online at www.national-academies.org/ilar, or contact ILAR for more information. Online Access: Both ILAR e-Journal and ILAR Journal articles are available online 6 months after publication, free of charge. Institutional members have immediate access to current issues. Permissions: Permission to use or reprint text or figures is granted for educational or research purposes only. Please call for more information. Copyright (c) 2009 ILAR. ILAR e-Journal ISSN 1930-6180. 


\title{
Validation of a Method for Measuring Sperm Quality and Quantity in Reproductive Toxicity Tests with Pair-Breeding Male Fathead Minnows (Pimephales promelas)
}

\author{
David N. Hala, Katrien Van Look, William V. Holt, and Susan Jobling
}

\begin{abstract}
The fathead minnow (Pimephales promelas) is an OECDproposed test species routinely used in reproductive toxicity trials with suspected endocrine-disrupting compounds (EDCs). The basic fecundity, endocrinology, and histopathology of reproductively active male and female fathead minnows has been well characterized, but there are few studies of the utility of male sperm concentration and motility as endpoints for use in reproductive trials. The purpose of this study was to (1) characterize the baseline sperm concentration and motility of pair-breeding male fathead minnows over their spawning cycle and (2) determine whether a repeated and nondestructive sperm sampling protocol would influence the baseline fecundity of the fish. Pair-breeding male fathead minnows that underwent sampling for milt three times a week for 4 weeks exhibited no significant changes in milt volume, sperm concentration, or motility parameters up to 6 days after each spawning event. The repeated sperm sampling procedure did, however, cause a significant lowering of spawning frequencies, although this decline did not correlate with effects on fecundity as there were no significant changes in the mean total numbers of eggs laid, fertilization, and hatching successes. This study confirmed the presence of a stable background of sperm concentration and motility parameters of pair-breeding male fathead minnows under reference conditions. The absence of any inherent "cycling" in the magnitude of these parameters over the spawning period suggests that sperm concentration and motility could be useful measures of male reproductive toxicity at the termination of tests in which pair-breeding males are at varying days post spawn.
\end{abstract}

Key Words: baseline; fathead minnow; nondestructive sampling; pair breeding; reproductive toxicity; spawn; sperm concentration; sperm motility

David N. Hala, MRes, PhD, was a postdoctoral researcher at the Institute for the Environment at Brunel University in Uxbridge, London (now a research scientist at the University of North Texas). Katrien Van Look, BSc Hons, PhD, was a postdoctoral research fellow at the Institute of Zoology of the Zoological Society of London and William V. Holt, PhD, is the Head of Reproductive Biology at the same institute. Susan Jobling, $\mathrm{PhD}$, is an academic at the Brunel University Institute for the Environment.

Address correspondence and reprint requests to Dr. Susan Jobling, Institute for the Environment, Brunel University, Uxbridge, London, UK UB8 3PH or email Susan.Jobling@Brunel.ac.uk.

${ }^{1}$ Abbreviations used in this article: ANOVA, analysis of variance; DPS, days post spawn; \%LIN, percentage straight-line velocity; \%MOT, percentage motility; VCL, curvilinear velocity; VSL, straight line-velocity

\section{Introduction}

$\mathrm{T}$ he literature reviewing the decline in human male reproductive health is extensive. Decreases in sperm concentration and motility appear to be subsidiary to a suite of etiological effects associated with the reproductive disorder termed testicular dysgenesis syndrome (TDS) (Carlsen et al. 1995; Irvine 1996, 2000, 2001; Jøgensen et al. 2006; Sharpe and Skakkebaek 2003). The criticality of hormonal cues in mediating the normal phenotypic development of male and female reproductive tissues has led to hypotheses implicating endocrinedisrupting chemicals (EDCs) as causative factors (Carlsen et al. 1995; Sharpe 1994; Sharpe and Irvine 2004). But as definitive data linking human reproduction disorders and diseases with exposure to endocrine disruptors are not available, most research has focused on wildlife epidemiology. In particular, studies have reported the feminization of male fish, lowered percentages of spermiating males, and reduced sperm concentration and fertilization rates in EDC-contaminated environments (Allen et al. 1999; Folmar et al. 1996; Harries et al. 1997; Jenkins et al. 2001; Jobling et al. 1998, 2002a,b; Keith 1998; Larsson et al. 1999, 2000; Lye et al. 1997; Orlando et al. 2002, 2004; Soto et al. 2004; Toft and Guillette 2005; Tyler et al. 1998). In general these studies suggest that EDC exposure can deleteriously affect sperm quality in fish, as in mammals, but current tests for fish do not include these parameters as endpoints. The aim of this study was to develop a methodology to measure sperm quality and quantity for use in reproductive toxicity tests in pair-breeding male fathead minnows.

The fathead minnow (Pimephales promelas) is an OECD-proposed test species routinely used in the conduct of reproductive toxicity trials with suspected EDCs (Ankley et al. 2001; Harries et al. 2000); the OECD-proposed 21-day fathead minnow test consists of monitoring the fecundity of adult males and females over a 21-day exposure period. Unlike mammalian male reproductive tests, however, the standard fish test protocol does not include measurements of male reproductive potential such as sperm quality nor methods to identify male- and femalespecific effects. One of the potential problems with measuring sperm quality and quantity in pair-breeding fish with very short reproductive cycles is that both parameters may vary over the spawning cycle. Reproductive toxicity tests for fathead minnows spans several spawning cycles (one event every $3.7 \pm 0.1$ days, according to Jensen et al. 2001) and at the termination of the 
test the male fish sampled are at different points in their natural cycles. The resulting natural variation in sperm quality and quantity may confound the results of any test in which sperm quality is used as a measure of toxicity.

Jensen and colleagues (2001) characterized the changes in basic endocrinology and biology of reproductively active male and female fathead minnows based on days post spawn (DPS ${ }^{1}$ ) and observed a significant elevation in the gonadosomatic indices (GSIs) of female fathead minnows at 2 DPS concomitant with elevated estradiol titers (which peaked at 1 DPS). They also reported a significant transition in the females' oocyte maturational stages: a dominance of primary growth stage oocytes after a spawning event, followed by the presence of vitellogenic oocytes 1 to 2 DPS. In contrast, observations revealed no significant changes of male GSI values and steroid titer concentrations of testosterone, 11-ketotestosterone, and estradiol over the spawning interval of up to 4 DPS. Histopathological changes in males after increasing numbers of DPS showed varied stages of spermatogenesis in the testes but, in contrast to the females, no distinctive transitional states between the various stages (Jensen et al. 2001). Similarly, Leino and colleagues (2004) showed that the vast majority of tubules in the male fathead minnow remained undiminished immediately after each spawning event, suggesting that sperm production and quality were unlikely to vary greatly during a normal spawning cycle. However, neither of these studies measured variability in sperm quantity and/or quality over the spawning period. A stable baseline of such parameters can allow for a robust comparison of the reproductive toxicological effects of a compound against a control group.

For our study we developed a method to nondestructively collect sperm from reproductively active male pair-breeding fathead minnows. The OECD-proposed 21-day fathead minnow test was adapted to allow the repeated sampling of male fish (3 times/week for 4 weeks) to assess changes in milt volume, sperm concentration, motility, and fertilization success with DPS.We also measured the potentially disruptive effects of handling stress on the reproductive competence of the pair-breeding fathead minnows by monitoring their fecundity, fertilization, and hatching successes.

\section{Materials and Methods}

\section{Fathead Minnow Stock Maintenance and Culture}

We used 12 pairs of actively (i.e., relatively frequently) spawning, pair-breeding adult fathead minnows, sourced from Osage Catfisheries (Osage Beach, Missouri) and placed in separate, 100-liter stock tanks. All fish were fed four times per day, twice with $\gamma$-irradiated frozen brine shrimp and twice with dry flake food. The fish were maintained at water temperatures of $25 \pm 1^{\circ} \mathrm{C}$ and on a day:night cycle of 16 hours light: 8 hours dark with a 15-minute dawn:dusk transition. The stock room system comprised a recirculation system in which the water was UV sterilized.

\section{Flow-Through System}

Each of the 12 glass tanks had a spawning substrate and a working volume of 8 liters under flow-through conditions. The substrate was made from black plastic gutter pipe on top of a perforated steel mesh affixed in a glass tray (using the method established by Harries et al. 2000). The flow-through design consisted of six glass tanks fed through six separate outflows emanating from a flow distribution chamber that itself received aquaria water from a header tank; two flow distribution chambers fed the 12 tanks with aquaria water. A flow meter controlled the flow of water into the distribution chamber to give a system flow rate of 36 liters/hour $(600 \mathrm{ml} / \mathrm{min})$ and an approximate flow rate of 100 $\mathrm{ml} / \mathrm{min}$ through each of the fish tanks.

\section{Anesthesia and Sperm Sampling Protocol}

The 12 males were sampled for milt 3 times a week(on consecutive days) over 4 weeks (this sampling regime conformed with UK Home Office regulations). The fish were mildly anesthetized with $100 \mathrm{mg} / 1$ ethyl 3-aminobenzoate methanesulfonate salt (MS-222; SIGMA, Cas. No. 886-86-2) buffered with 0.5 molar (M) sodium bicarbonate (SIGMA, Cas. No. 144-55-8). Once the male appeared to be listing and hence under anesthesia (usually within $1 \mathrm{~min}$ ), it was removed from the anesthetic solution and its ventral surface dried with absorbent paper; excess water droplets may not only make handling difficult but also activate sperm motility by contaminating the milt sample with water. The male was then placed on its dorsal surface and held firmly in a slit (approximately 2 " deep) in an ordinary domestic dishwashing sponge. This enabled the quick and effective removal of milt as the urogenital papilla was accessible and in clear view. The lower abdomen surrounding the urogenital opening was again dried of excess moisture. Milt was obtained from each fish by gently compressing the abdomen unidirectionally from just below the pectoral fins to just before the urogenital opening. The ejaculated milt (a white viscous fluid) was collected using a $5 \mu$ graduated capillary tube (Aldrich, Z611239-250EA) and its volume noted. The collected milt was expelled into a microfuge tube and diluted 1:50 in cold catfish extender (94 millimolars, or $\mathrm{mM}$, sodium chloride, $27 \mathrm{mM}$ potassium chloride, $15 \mathrm{mM}$ trizma hydrochloric acid, and $50 \mathrm{mM}$ glycine $\mathrm{pH}$ to 7.5 ) and then stored at $4^{\circ} \mathrm{C}$ pending analysis of density and motility. The sampled male was placed in a temporary holding tank (approximate volume of 2 liters) containing the aquaria header tank water. Once the male recovered (in $<1 \mathrm{~min}$ ), it was replaced in its spawning tank before the sampling of the next male. The males were always sampled during the "night" photoperiod to offset potential diurnal behavioral cues and minimize handling stress. 


\section{Sperm Cell Concentration Assessment}

Sperm counts were conducted on a Neubauer hemocytometer by diluting the already diluted milt (1:50) a further 1:2 in cold catfish extender $(10 \mu \mathrm{l}$ diluted milt $+10 \mu \mathrm{l}$ extender $)$ in a microfuge tube. A $15 \mu \mathrm{l}$ aliquot of this diluted milt was allowed to flood one chamber of the Neubauer hemocytometer (using a hand-held pipette). After 1 to 2 minutes (for the cells to settle), sperm cells were counted on an Olympus (BX50) microscope (with a 440 objective) coupled to a camera and JVC TV monitor. Sperm cells in the central grid of 25 hatched $(5 \times 5)$ squares of the flooded chamber were observed and counted, beginning in the top left square of the grid, using the following rules:

- If $<10$ spermatozoa were counted in this first square, then a total cell count was conducted in all 25 squares and averaged.

- If 10 to 40 spermatozoa were counted, then total counts in 10 squares were averaged.

- If $>40$ spermatozoa were counted, then total counts of 5 squares were averaged.

The averaged sperm count in the 25 -square grid $(0.1 \mu \mathrm{l})$ was expressed as counts $\times 10^{4}$ cells $/ \mathrm{ml}$. This count was in turn corrected for the 1:50 dilution of milt in extender and then the $1: 2$ dilution before conducting the cell counts.

\section{Sperm Motility Assessment}

A video camera-mounted microscope (negative phase contrast with a heated stage) attached to a monitor and compact disc (CD) recorder was used to observe and record the motility of the fathead minnow spermatozoa. Diluted milt samples (1:50) in microfuge tubes were resuspended (using a vortexer) and a $10 \mu \mathrm{l}$ aliquot of the sperm suspension in extender was diluted a further 1:2 with $10 \mu \mathrm{l}$ of aquaria tank water (at $25^{\circ} \mathrm{C}$ ) to induce motility. Immediately after this dilution, a $1 \mu$ aliquot was taken and placed in a single well of a dipped multiwell slide (12-Well Multi-Test Slide, ICN Biomedicals Inc., Costa Mesa, Calif., Cat. No. 6041205E) and covered with a bovine serum albumin (BSA; SIGMA, Cas. No. 9048-46-8) coated coverslip that was prepared by washing in $1 \%$ BSA. Motile sperm cells visible in the frame of view (x10 objective with a 2.2 column) were recorded for 5 minutes (the heated stage of the microscope was maintained at $25^{\circ} \mathrm{C}$ for the duration of the recording). To avoid cell drift, which would give a false motility value for nonmotile cells, we ensured an even dispersion of the aliquot while placing the coverslip. The induction of sperm cell motility and slide preparation for the recording of the motility images took about 5 seconds for each fish.

\section{Sperm Tracking and the CASA System}

The sperm in each milt sample were activated by dilution $(1: 1)$ in aquaria waters. We tracked the sperm using the Hobson Sperm
Tracker (Hobson Vision Systems, Sheffield, UK) and recorded sperm movement using the computer-assisted sperm analysis (CASA) system (a microscope mounted with a video camera, used in negative phase). The recordings replayed and tracked for set time increments using a software that tracks individual spermatozoa and that calculated various motility parameters (Kime et al. 2001). The recorded sperm quantity and quality parameters included milt volume $(\mu \mathrm{l})$ and sperm concentration (cells $/ \mathrm{ml}$ ), in addition to the following motility parameters:

- $\mathrm{VCL}^{1}=$ curvilinear velocity ( $\mu \mathrm{m} / \mathrm{seconds}$ ), the sum of incremental distances moved by a spermatozoa along a trajectory for each time frame divided by the time taken to cover that trajectory;

- $\mathrm{VSL}^{1}=$ straight-line velocity ( $\left.\mu \mathrm{m} / \mathrm{seconds}\right)$, the straightline distance between the start and end of a trajectory divided by the total track time;

- $\% \mathrm{LIN}^{1}=$ percentage linearity of motion, the straight-line distance $(\mu \mathrm{m})$ between the start and endpoints of a track divided by the sum of the incremental distances along the trajectory; and

- $\% \mathrm{MOT}^{1}=$ percent motility, based on the number of motile cells divided by the total numbers of cells (motile and immotile) visible in the analysis field.

The recorded video sequences of motile sperm cells were tracked in 15-second increments (the Hobson Sperm Tracker cannot be used to calculate the percentage of motile sperm for shorter intervals; Kime et al. 2001). However, there is a relatively high tracking resolution within the 15 -second time frame as the tracked coordinates (on the $\mathrm{x}$ and $\mathrm{y}$ axes) of motile spermatozoa are recorded every $1 / 50$ of a second (with the system operating at $50 \mathrm{~Hz}$ ). Preliminary analysis of the changes in motility over time facilitated the selection of a sperm tracking duration that would not be confounded by any natural changes (such as a decrease) in sperm velocity. We determined the tracking duration by quantifying the changes in motility over 4 minutes (240 seconds) for each of the 12 males on a randomly selected sampling day (using the random number selector function in SPSS). This assessment ensured analysis of the data without the potential bias that might result from selecting for a particular day after spawn or any other sampling specification.

\section{Changes in DPS Sperm Motility Measures}

We assessed the effects of DPS on the milt volume, sperm concentration, and progressive motility parameters by pooling and sorting the concentration and motility data over the 4-week sampling period into DPS categories from day 0 (i.e., sampling within 24 hours of a spawning event) to DPS 1 through 6 . We chose these days for analysis as they incorporated the average spawning frequency of between 3 and 5 days for reproductively active fathead minnows (Jensen et al. 2001). The numbers of sampled males for each DPS were 0 DPS $=9 ; 1$ DPS $=11 ; 2$ $\mathrm{DPS}=8 ; 3 \mathrm{DPS}=8 ; 4 \mathrm{DPS}=9 ; 5 \mathrm{DPS}=3$; and $6 \mathrm{DPS}=7$. We 
also investigated the effects of intermale (or -tank) variability on the motility measures.

\section{Fecundity and Hatching Successes}

We recorded egg counts and spawning frequencies daily. The fertilization success (\%) of each male was quantified with each spawned batch of eggs, expressed as a percentage of opaque eggs relative to the total numbers of eggs laid. In contrast, the hatching success (\%) was quantified for alternate batches of spawned eggs (assessed on DPS 1, 3, and 5). Spawned eggs (both viable and nonviable) used for a hatching success study were first quantified for a total count. The eggs oviposited on the spawning substrate were then returned to the tank for 24 hours to allow the male fathead minnows to "groom" the clutches of fungi-infected eggs. We then re-counted the eggs to tally surviving or embryonic eggs versus nonviable eggs and placed all eggs in a stainless steel mesh hatching basket suspended in the same 8-liter tank as the spawning adults. The hatchlings were quantified over a period of 5 days and the results expressed as a percentage of the eggs fertilized (or counted as opaque on the day spawned). This approach has resulted in greater than $90 \%$ hatching successes in our studies.

\section{Statistical Analyses}

We used JMP.IN version 5.1 for the statistical data analyses and tabulated the individual motility measures for all 12 males for each DPS. The distribution of these stacked individual values was first investigated as this would dictate the use of either nonparametric (using median data) or parametric tests (using mean data). The analysis of variance (ANOVA ${ }^{1}$ ) and associated multiple comparisons were conducted where the normality and equal variances of data could be confirmed. For nonnormal distributions we conducted the Kruskall-Wallis test on the rank scores. Datasets conforming to parametric assumptions are shown in Figure 1 as bar graphs with average + standard errors and nonparametric datasets as box and whisker plots displaying median, lower 25th, and upper 75th quantile ranges. The nonparametric Friedman's two-way ANOVA was conducted to test the effects of "tank" and "DPS" on the motility parameters. The analysis also included an interaction model of the two effect parameters.

\section{Results}

The changes in the progressive motility parameters of VCL, VSL, \%LIN, and \%MOT over a 4-minute tracking duration (in 15 -second increments) are plotted in Figure 1. We used two-way ANOVAs to investigate the effects of time and intertank/ -male variability on the motility measurements. Analysis of the VCL and VSL measures, respectively, over the 4-minute tracking period revealed no significant changes $(p=0.75$ and 0.83$)$ nor any based on intertank/-male differences $(p=0.31$ and $0.22)$. The interaction term of the two effects parameters also showed no significant effects $(p=1.0$ and 0.99$)$. Additionally, a parametric, two-way ANOVA of the \%MOT measures showed no significant effects of time and intertank/-male variability $(p=0.98$ and 0.12$)$. The interaction of the two variables also showed no significant effects $(p=0.99)$.

The percentage linearity (\%LIN) measures, however, showed a nonnormal distribution. To investigate the potential effects of time and intertank variability on these values using a two-way ANOVA platform we ranked the \%LIN measures for each time increment. This allowed for the use of the Friedman's two-way ANOVA on the ranked velocity measures. There were no significant effects of time or intertank/-male variability on the \%LIN values ( $p=0.95$ and 0.33 ), and the interaction model of the two variables also showed no significant effects $(p=$ $0.76)$. On the basis of these results and the realization of the long motility duration of fathead minnow spermatozoa (compared with other cyprinids), we selected a standard motility tracking duration of 2 minutes for all subsequent analyses.

We also tested correlations between the various motility parameters by conducting a logarithmic transformation (base 10) of the listed mean and median measures for each tank, with tracking time frames from 15 to 240 seconds. The distribution of this log-transformed data was nonnormal, so we used the nonparametric Spearman's rho multivariate correlation test, which showed that all motility values were positively correlated with one another $(p<0.0001)$. Sperm concentration and motility values were also correlated with the numbers of eggs spawned and fertilized on the day of spawning (0 DPS). Interestingly, all of the measured sperm motility values showed negative correlations ( $\mathrm{R} 2=-0.39$ to -0.67$)$ with the fertilization success of the eggs spawned, although only the \%MOT values showing a statistically significant negative correlation $(\mathrm{R} 2=-0.67, p=$ 0.05 ) at the $95 \%$ level. There were no significant correlations between sperm cell density and percentage fertilization success ( $\mathrm{R} 2=-0.05, p=0.89)$. The latter correlated positively and significantly with the numbers of eggs spawned by the females (Spearman's rho $=0.77, p=0.016$ ).

\section{Potential Effects of Time of Sampling (DPS) on Sperm Concentration and Motility Parameters}

The changes in milt volume, sperm concentration, and motility with DPS are shown in Figure 2. The parametric one-way ANOVA indicated no significant differences in the milt volumes sampled at the various DPS $(p=0.98)$ and the nonparametric Kruskall-Wallis test showed no significant differences of the sperm cell concentration measures with DPS $(p=0.47)$. A nonparametric Friedman's two-way ANOVA was conducted on the ranked median motility values of VCL, VSL, \%LIN, and \%MOT for each DPS. We also investigated the effects of DPS and intertank/-male variability on the response variables of VCL, VSL, \%LIN, and \%MOT and found no significant 
(a)

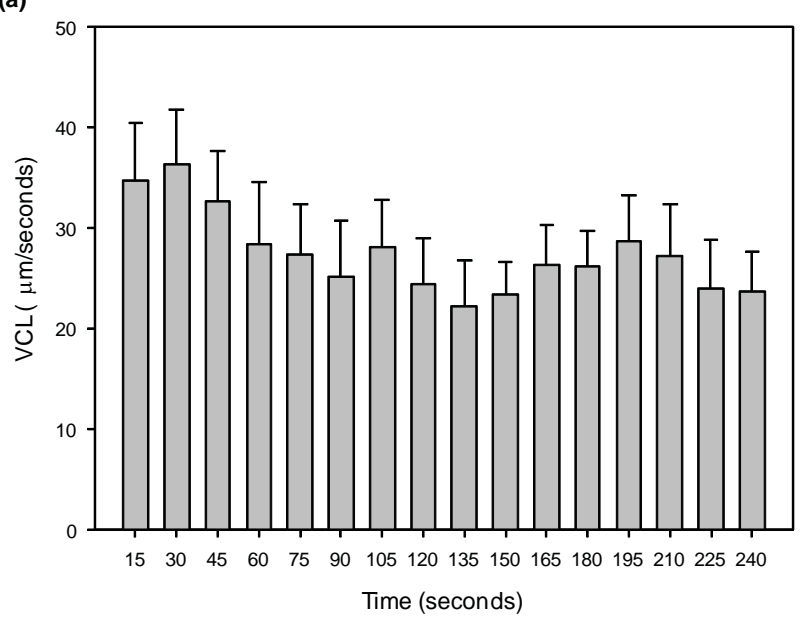

(c)

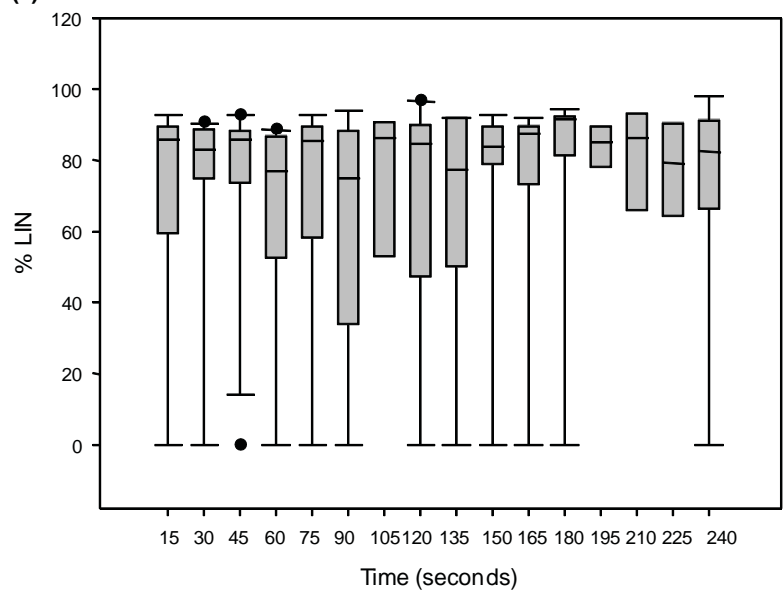

(b)

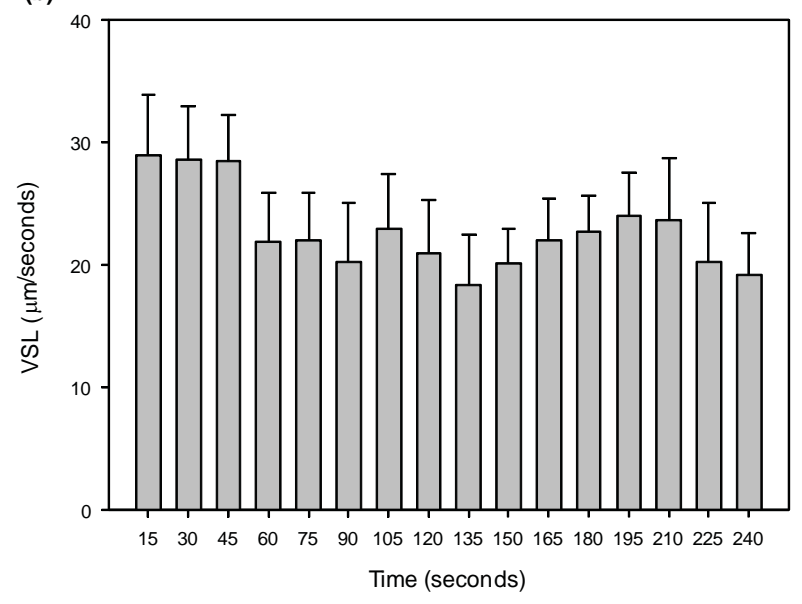

(d)

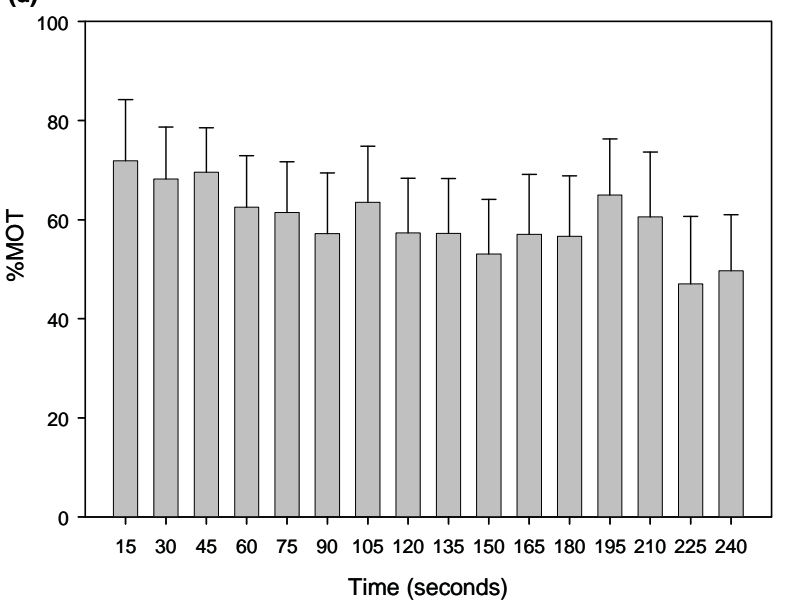

Figure 1 Progressive motility values of (a) curvilinear velocity (VCL), (b) straight-line velocity (VSL), (c) percentage linearity (\%LIN), and (d) percentage motility (\%MOT) for the spermatozoa of 12 pair-breeding male fathead minnow tracked for the first 4 minutes ( 240 seconds) of motility. Parametric datasets are shown as average + standard errors, nonparametric datasets as box and whisker plots showing the median values with the 25 th and 75th percentile quantile ranges; black dots represent values at or outside the variance limits of the quantile ranges.

effects of DPS $(p>0.05)$ or tanks $(p>0.05)$. The inclusion of an interaction term between the two parameters also showed no significant effects on motility $(p>0.05)$.

Thus it seems that there are no significant effects of DPS or intertank/-male variability on the sperm motility parameters of VCL, VSL, \%LIN, and \%MOT of pair-breeding male fathead minnows. This finding suggests that all males can be sampled at the same time after termination of a reproductive toxicity trial regardless of the time of their last spawning event.

\section{Effects of the Repeated Sampling Protocol on Fecundity and Reproductive Competence}

We analyzed changes in the spawning frequencies, mean total egg counts, fertilization success, and hatching success for all
12 pair-breeding fathead minnows during the 4-week study (Figure 3).

The nonparametric Kruskal-Wallis test indicated a significant effect of the sampling procedure on spawning frequency $(p=0.028)$. Dunnett's multiple comparison, with week 1 as the control group, showed weeks 2 and 4 as significantly different from weeks 1 and $3(p=0.02$ and 0.01$)$. However, in contrast to the frequency of one spawning event every 3 to 4 days for reproductively active fathead minnows (Jensen et al. 2001), we observed an overall lower frequency of 1.3 spawning events every 7 days (indicating that each male, on average, spawned at least once per week over the 4-week study). There were, however, no effects of the sampling procedure on the mean total egg counts of the 12 pairs of fish over the 4 -week period (ANOVA, $p=0.61$ ). Similarly, we observed no 
(a)

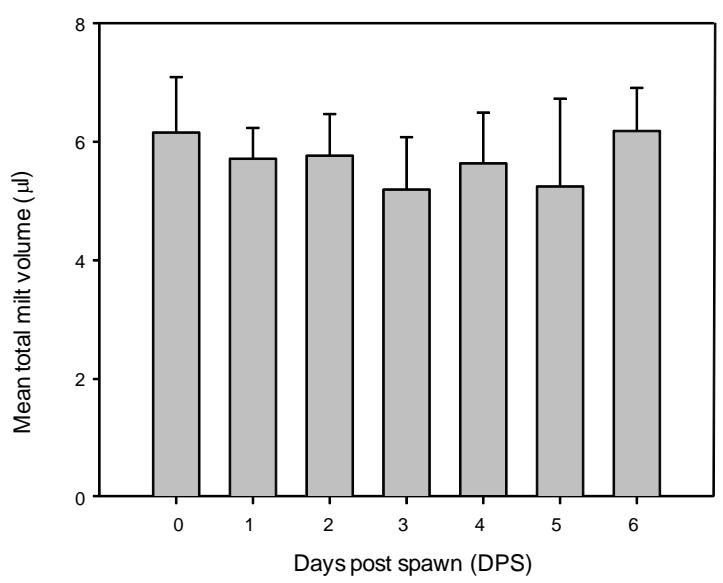

(c)

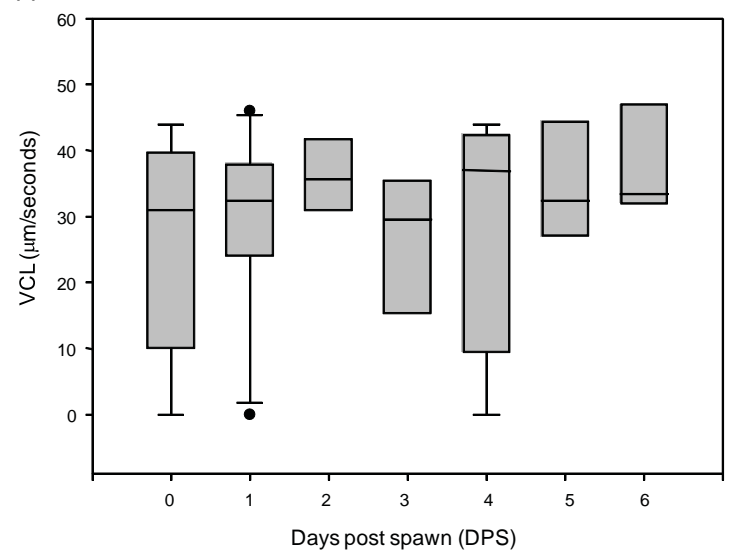

(e)

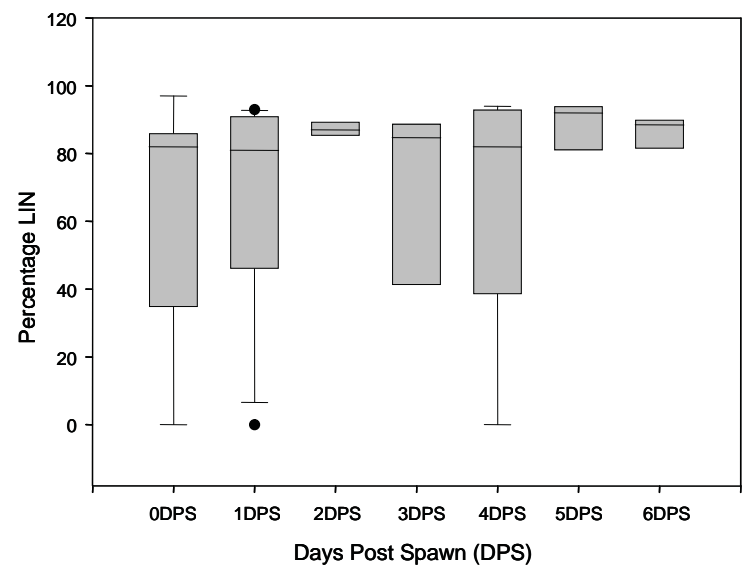

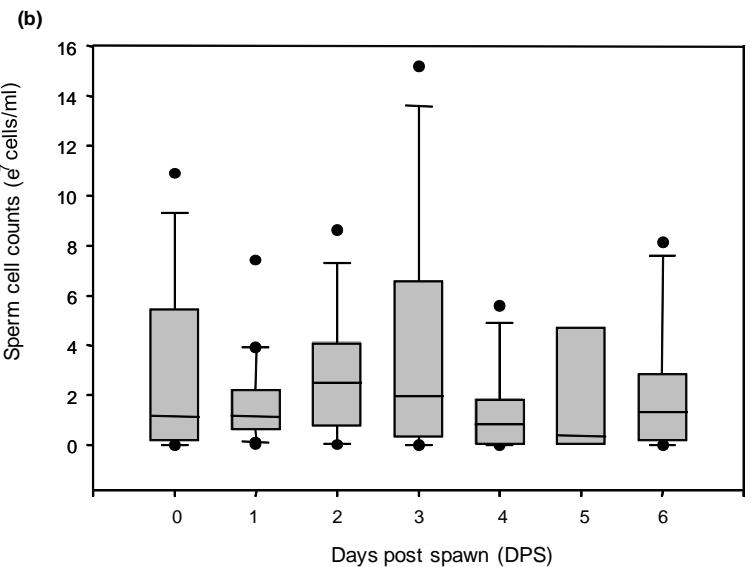

(d)

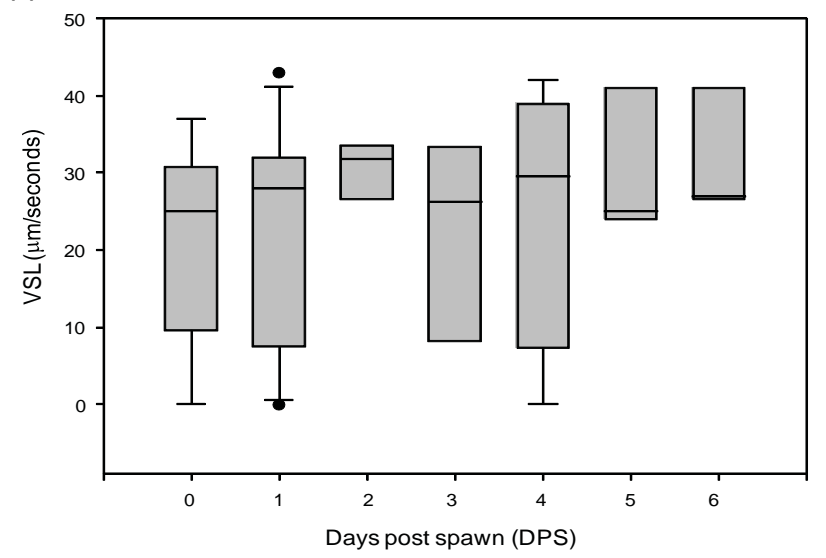

(f)

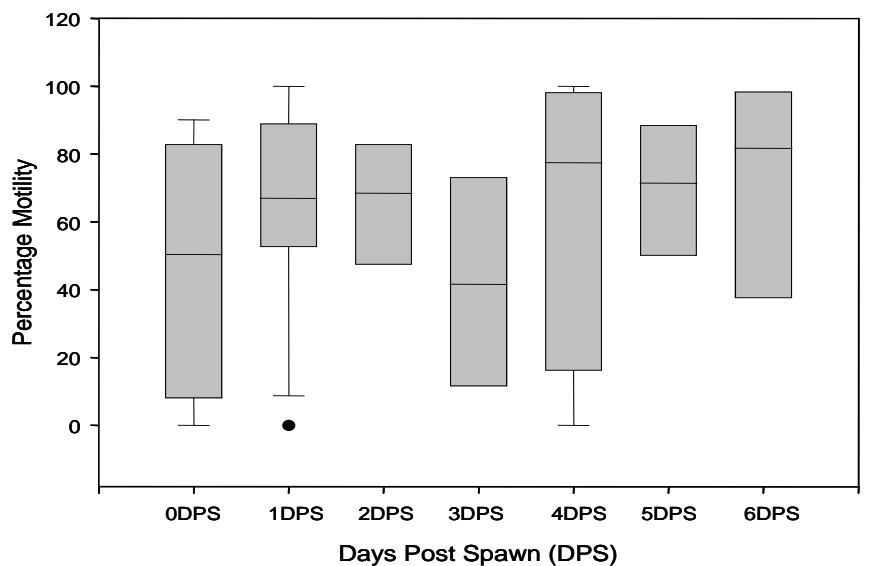

Figure 2 Changes in (a) milt volume, (b) sperm cell concentration, (c) curvilinear velocity (VCL), (d) straight-line velocity (VSL), (e) percentage linearity $(\% \mathrm{LIN})$, and (f) percentage motility (\%MOT) of pair-breeding male fathead minnows up to 6 days post spawn. Parametric datasets are shown as average + standard errors, nonparametric datasets as box and whisker plots showing the median values with the 25 th and 75 th percentile quantile ranges; black dots represent values at or outside the variance limits of the quantile ranges. 
significant changes in fertilization success (Kruskal-Wallis, $p$ $=0.53$ ) or percentage hatching success of the spawned eggs (Wilcoxon rank sum test, $p=0.47$ ).

\section{Discussion}

In this study we aimed to (1) establish a method for sampling sperm in pair-breeding fathead minnows and (2) evaluate the possible cycling of sperm concentration and motility during successive reproductive cycles over the normal period of a reproductive toxicity test. Our strategy involved the nondestructive sampling of males for milt on 3 consecutive days per week for 4 weeks.

The study demonstrated the long motility duration of fathead minnow spermatozoa, with no significant changes in the sperm motility parameters of curvilinear velocity (VCL),

(a)

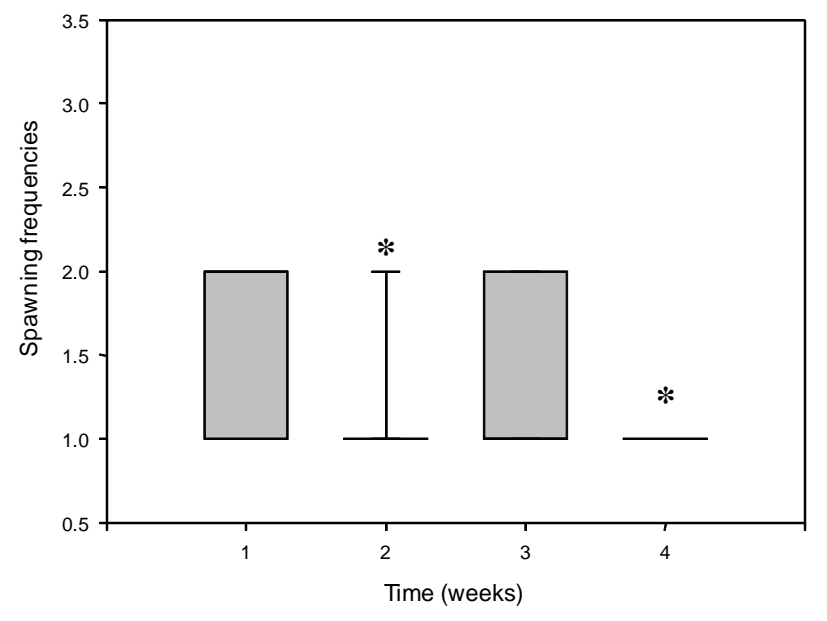

(c)

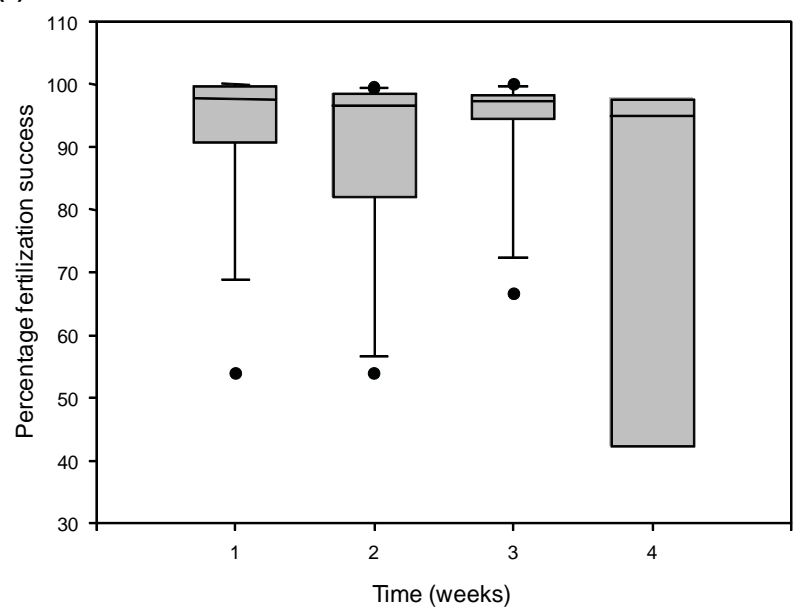

straight-line velocity (VSL), percentage linearity of motion $(\% \mathrm{LIN})$, and percentage motile cells (\%MOT) during the first 4 minutes of tracking. This duration of sperm motility is much longer than described for other fish species (generally less than 2 minutes) (Kime et al. 2001; Rurangwa et al. 2004) and is a possible reflection of the spawning strategy of fathead minnows. The males establish territories around spawning sites (Cole and Smith 1987) and do not leave them to pursue mature females that are ready to spawn; rather, they fertilize the eggs oviposited by the females and guard them until hatching. Thus there may not be a need to evolve spermatozoa that are highly motile for a short duration following ejaculation, as there is no intermale sperm competition as would be expected in broadcast or group spawners such as roach or salmon (Cole and Smith 1987; Gage et al. 2004). Furthermore, multivariate correlations of the various motility parameters showed a positive and significant correlation among all four measures (VCL, VSL, $\% \mathrm{LIN}$, and \%MOT). The significant correlation of the VCL and

(b)

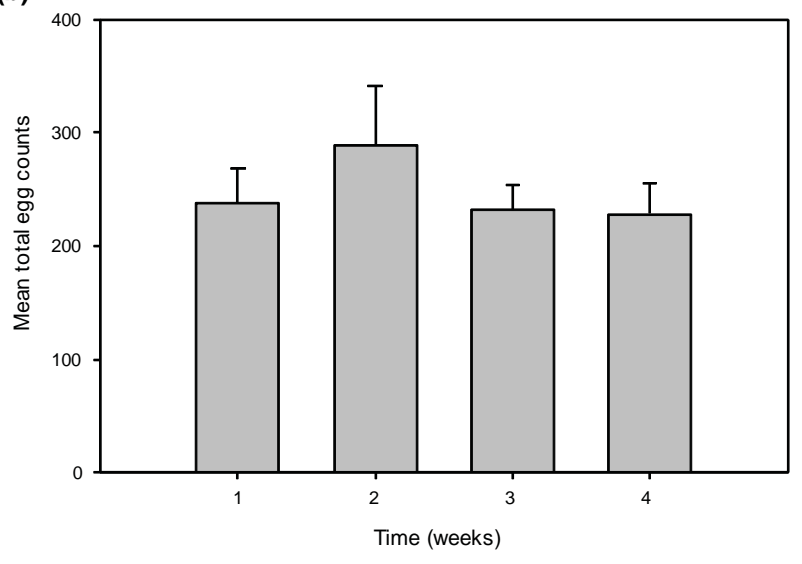

(d)

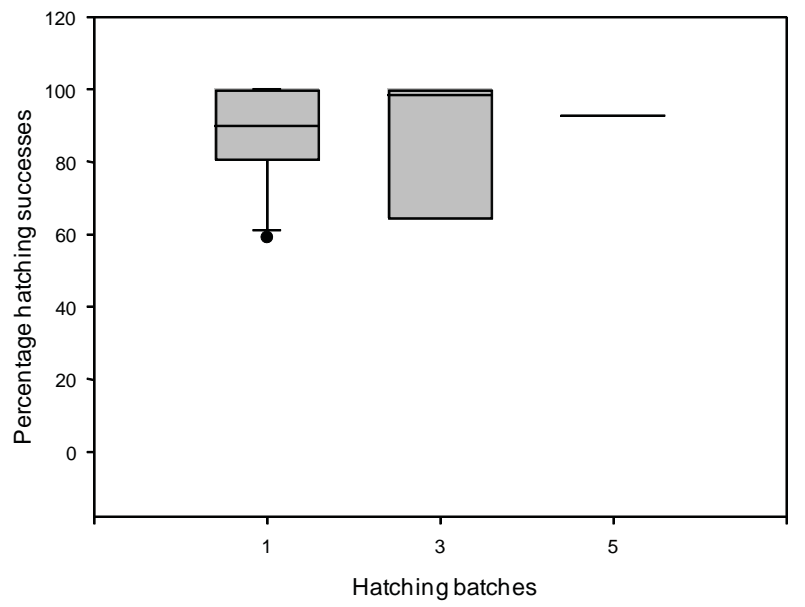

Figure 3 Overall changes in (a) spawning frequencies, (b) mean total egg counts, (c) percentage fertilization success, and (d) percentage hatching success of 12 pair-breeding male fathead minnows over the 4-week study period. Parametric datasets are shown as average + standard errors, nonparametric datasets as box and whisker plots showing the median values with the 25th and 75th percentile quantile ranges; black dots represent values at or outside the variance limits of the quantile ranges; * designates significantly different results. 
VSL measures indicates that the trajectory of fathead minnow spermatozoa is mainly straight-line (Rurangwa et al. 2004).

Of great interest were the negative correlations of sperm motility values with the percentage fertilization success of the eggs laid. These findings are contrary to those reported by Gage and colleagues (2004): in their in vitro fertilization trials using Atlantic salmon (Salmo salar) sperm and eggs they demonstrated that spermatozoa with faster velocities correlated with higher fertilization successes. Fertilization trials conducted by Kupriyanoya and Havenhand (2002), with the marine invertebrate polychaete Galeolaria caespitose, have also shown a positive and significant correlation between fertilization success and sperm velocity $(p=0.014)$. In contrast, we found no significant correlations between sperm motility (\%MOT) and fertilization success $(p=0.85)$. It is difficult to speculate on the reasons for the negative correlations in our study as it is unlikely that highly motile spermatozoa would be less efficient at fertilizing eggs, although the correlation may reflect the male fathead minnow spawning strategy (i.e., the absence of intermale sperm competition would not require the evolution of highly motile spermatozoa).

It is possible that in a pair-breeding spawning strategy longevity of sperm motility is a greater determinant of fertilization success. We demonstrated the longevity of male fathead minnow spermatozoa by the absence of significant changes in motility over a 4-minute tracking duration (the lack of decrease in the measured motility values indicates not only the persistence of the motility but also the longevity of the sperm). The significant positive correlation between fertilization success and the number of eggs spawned may be a result of the behavioral "coupling" of pair-breeding fathead minnows. Their spawning involves simultaneous oviposition (by the female) and release of milt (by the male), and the duration necessitated by the female's highly fecund spawning event may potentiate a higher male fertilization rate because of this mutual dependence (Cole and Smith 1987; Denny 1987).

No significant correlations between sperm cell concentration and fertilization success were evident for the males sampled on the day of a spawning event (DPS 0). Rurangwa and colleagues (1998), under in vitro conditions, demonstrated that an optimum sperm:egg ratio for the fertilization of African catfish (Clarias gariepinus) eggs was 15000:1; higher and lower ratios resulted in lower fertilization successes. In contrast, Tvedt and colleagues (2001), using spermatozoa and eggs from the Atlantic halibut (Hippoglossus hippoglossus), failed to demonstrate an optimum ratio for concentrations varying from $4.6 \mathrm{e} 8$ to $9.4 \mathrm{e} 5$ spermatozoa:egg; and Gage and colleagues (2004) demonstrated that relative sperm cell concentrations have no significant effects on the fertilization successes of Atlantic salmon eggs.

We noted a lack of a significant cycling of milt volume, sperm concentration, and motility values based on DPS of male pair-breeding fathead minnows. Our statistical analyses also showed that intertank and -male variability did not significantly influence density and velocity measures. The results indicate that fathead minnows maintained under optimal conditions of a "summer" photoperiod and temperatures do not show significant variation in their sperm concentration and motility parameters for up to 6 days after their last spawning event. These observations are in agreement with the reported absence of changes in the gonadal histopathology and endocrinology of fathead minnows under laboratory conditions.

We investigated the influence of the repetitive sampling routine on the fecundity, spawning frequencies, fertilization success, and hatching successes of pair-breeding fathead minnows. We noted a significantly lower spawning frequency for weeks 2 and 4 of the study relative to weeks 1 and 3 . These lower frequencies did not, however, equate to a lowered mean total numbers of eggs spawned by the females, suggesting that, although there were fewer spawning events in the second and fourth weeks of the study, the females were laying more eggs per event. The reduced spawning frequency may have been a male-specific effect, possibly due to the stress of their repeated handling. No significant changes in the overall fertilization or hatching rates were evident during the 4-week study, thus suggesting the absence of any overall deleterious effects on the reproductive competence of the pair-breeding fish.

Stress has been shown to suppress plasma testosterone and 11-ketotestosterone concentrations in male rainbow trout (Salmo trutta). The suppression of such androgen titers and elevations in cortisol and gonadotrophin concentrations have been associated with reduced reproductive competence in fish (Carragher and Sumpter 1990; Pickering et al. 1987). For example, male and female rainbow trout subjected to repeated acute stress (removal from aquaria waters for 3 minutes) during reproductive development showed significant changes when they reached sexual maturity - among the females, delays in ovulation and reduced egg size, and in the males significantly lower sperm cell counts. Lower survival rates of the F1 progeny were also reported after in vitro spawning trials using the eggs and sperm of the stress-subjected fish (Campbell et al. 1992).

\section{Conclusion}

This study describes a nondestructive, repeatable sampling protocol for obtaining milt from pair-breeding fathead minnows. A tracking duration of 2 minutes for assessing sperm motility was also validated. The results revealed the lack of a significant "cycling" in the sperm concentration and motility values up to 6 days post spawn and therefore confirmed that these parameters could be a reliable endpoint in fathead minnow reproductive toxicity tests.

\section{Acknowledgments}

The research described was funded by theEU project Comparative Research on Endocrine Disrupters (COMPRENDO), contract No. EVK1-CT-2002-00129. 


\section{References}

Allen Y, Scott A, Matthiessen P, Haworth S, Thain J, Feist S. 1999. Survey of estrogenic activity in United Kingdom estuarine and coastal waters and its effects on gonadal development of the flounder Platichthys flesus. Environ Toxicol Chem 18:1791-1800.

Ankley G, Jensen K, Kahl M, Korte J. Makynen E. 2001. Description and evaluation of a short-term reproduction test with the fathead minnow (Pimephales promelas). Environ Toxicol Chem 20:12761290.

Campbell P, Pottinger T, Sumpter J. 1992. Stress reduces the quality of gametes produced by rainbow trout. Biol Reprod 47:1140-1150.

Carlsen E, Giwercman A, Keiding N, Skakkebaek N. 1995. Declining semen quality and increasing incidence of testicular cancer: Is there a common cause? Environ Health Persp 103:137-139.

Carragher J, Sumpter J. 1990. The effect of cortisol on the secretion of sex steroids from cultured ovarian follicles of rainbow trout. Gen Comp Endocrinol 77:403-407.

Cole K, Smith J. 1987. Male courting behaviour in the fathead minnow Pimephales promelas. Environ Biol Fish 18:235-239.

Denny J. 1987. Guidelines for the Culture of Fathead Minnows Pimephales Promelas for Use in Toxicity Tests (EPA/600/387/001). Washington: US Government Printing Office. p 1-42.

Folmar L, Denslow N, Rao V, Chow M, Crain D, Enblom J, Marcino J, Guillette L. 1996. Vitellogenin induction and reduced serum testosterone concentrations in feral male carp (Cyprinus carpio) captured near a major metropolitan sewage treatment plant. Environ Health Persp 104:1096-1101.

Gage M, MacFarlane C, Yeates S, Ward R, Searle J, Parker G. 2004. Spermatozoal traits and sperm competition in Atlantic salmon: Relative sperm velocity is the primary determinant of fertilization success. Curr Biol 14:44-47.

Harries J, Sheahan D, Jobling S, Matthiessen P, Neall P, Sumpter J, Tylor T, Zaman N. 1997. Estrogenic activity in five United Kingdom rivers detected by measurement of vitellogenesis in caged male trout. Environ Toxicol Chem 16:534-542.

Harries J, Runnalls T, Hill E, Harries C, Maddix S, Sumpter J, Tyler C. 2000. Development of a reproductive performance test for endocrine disrupting chemicals using pair-breeding fathead minnows (Pimephales promelas). Environ Sci Technol 34:30033011.

Irvine D. 1996. Is the human testis still an organ at risk? Brit Med J 312:1557-1558.

Irvine D. 2000. Male reproductive health: A cause for concern? Andrologia 32:195-208.

Irvine D. 2001. Changing male reproductive health: A review of the clinical evidence? Hum Ecol Risk Assess 7:1003-1016.

Jenkins R, Angus R, McNatt H, Howell W, Kemppainen J, Kirk M, Wilson E. 2001. Identification of androstenedione in a river containing paper mill effluent. Environ Toxicol Chem 20:13251331.

Jensen K, Korte J, Kahl M, Pasha M, Ankley G. 2001. Aspects of basic reproductive biology and endocrinolgy in the fathead minnow (Pimephales promelas). Comp Biochem Phys C 128:127-141.

Jobling S, Nolan M, Tyler C, Brighty G, Sumpter J. 1998. Widespread sexual disruption in wild fish. Environ Sci Technol 32:2498-2506.
Jobling S, Beresford N, Nolan M, Rodgers-Gray T, Brighty G, Sumpter J, Tyler C. 2002a. Altered sexual maturation and gamete production in wild roach (Rutilus rutilus) living in rivers that receive treated sewage effluents. Biol Reprod 66:272-281.

Jobling S, Coey S, Whitmore J, Kime D, Van Look K, McAllister B, Beresford N, Henshaw A, Brighty G, Tyler C, Sumpter J. 2002b. Wild intersex roach (Rutilus rutilus) have reduced fertility. Biol Reprod 67:515-524.

Jøgensen N, Asklund C, Carlsen E, Skakkebaek N. 2006. Coordinated European investigations of semen quality: Results from studies of Scandinavian young men are a matter of concern. Int J Androl 29:54-61.

Keith L. 1998. Environmental endocrine disruptors. Pure Appl Chem 70:2319-2326.

Kime D, Van Look K, McAllister B, Huyskens G, Rurangwa E, Ollevier F. 2001. Computer-assisted sperm analysis (CASA) as a tool for monitoring sperm quality in fish. Comp Biochem Phys C 130:425433.

Kupriyanoya E, Havenhand J. 2002. Variation in sperm swimming behaviour and its effect on fertilization success in the serpulid polychaete Galeolaria caespitose. Invertebr Reprod Dev 41:21-26.

Larsson D, Adolfsson-Erici M, Parkkonen J, Pettersson M, Berg A, Olsson P, Forlin L. 1999. Ethinyloestradiol: An undesired fish contraceptive? Aquat Toxicol 45:91-97.

Larsson D, Hällman H, Förlin L. 2000. More male fish embryos near pulp mill. Environ Toxicol Chem 19:2911-2917.

Leino R, Jensen K, Ankley G. 2004. Gonadal histology and characteristic histopathology associated with endocrine disruption in the adult fathead minnow (Pimephales promelas). Environ Toxicol Phar 19:85-98.

Lye C, Frid C, Gill M, McCormick D. 1997. Abnormalities in the reproductive health of flounder Platichthys flesus exposed to effluent from a sewage treatment works. Mar Pollut Bull 34:34-41.

Orlando E, Davis W, Guillette L. 2002. Aromatase activity in the ovary and brain of the eastern mosquitofish (Gambusia holbrooki) exposed to paper mill effluent. Environ Health Persp 110:429-433.

Orlando E, Kolok A, Binzcik G, Gates J, Horton M, Lambright C, Gray L, Soto A, Guillette L. 2004. Endocrine-disrupting effects of cattle feedlot effluent on an aquatic sentinel species the fathead minnow. Environ Health Persp 112:353-358.

Pickering A, Pottinger T, Carragher J, Sumpter J. 1987. The effects of acute and chronic stress on the levels of reproductive hormones in the plasma of mature male brown trout Salmo trutta L. Gen Comp Endocr 68:249-259.

Rurangwa E, Roelants I, Huyskens G, Ebrahimi M, Kime D, Ollevier F. 1998. The minimum effective spermatozoa:egg ratio for artificial insemination and the effects of mercury on sperm motility and fertilization ability in Clarias gariepinus. J Fish Biol 53:402-413.

Rurangwa E, Kime D, Ollevier F, Nash J. 2004. The measurement of sperm motility and factors affecting sperm quality in cultured fish. Aquaculture 1:1-28.

Sharpe R. 1994. Could environmental, oestrogenic chemicals be responsible for some disorders of human male reproductive development? Curr Opin Urol 4:295-301.

Sharpe R, Irvine S. 2004. How strong is the evidence of a link between environmental chemicals and adverse effects on human 
reproductive health? Brit Med J 328:447-451.

Sharpe R, Skakkebaek N. 2003. male reproductive disorders and the role of endocrine disruption: Advances in understanding and identification of areas for future research. Pure Appl Chem 75:2023-2038.

Soto A, Calabro , Prechtl N, Yau A, Orlando E, Daxenberger A, Kolok A, Guillette L, Bizec B, Lange I, Sonnenschein C. 2004. Androgenic and estrogenic activity in water bodies receiving cattle feedlot effluent in eastern Nebraska USA. Environ Health Persp 112:346-352.

Toft G, Guillette L. 2005. Decreased sperm count and sexual behaviour in mosquitofish exposed to water from a pesticide-contaminated lake. Ecotox Environ Safe 60:15-20.

Tvedt H, Benfey T, Martin-Robichaud D, Power J. 2001. The relationship between sperm density, spermatocrit, sperm motility and fertilisation success in Atlantic halibut Hippoglossus hippoglossus. Aquaculture 194:191-200.

Tyler C, Jobling S, Sumpter J. 1998. Endocrine disruption in wildlife: A critical review of the evidence. Crit Rev Toxicol 28:319-361. 